\title{
An Evaluation of Intelligibility Debate in Pakistan
}

\author{
Rehana Yasmin Anjum \\ Asst Prof. of English \\ Govt College Women University, Sialkot. \\ Siakot, Pakistan.
}

\begin{abstract}
The English language came to the subcontinent through the British who ruled it for more than 100 years in the 17th century. Now the people of Pakistan and India are sandwiched between a more formal, sophisticated and literal English Language of the British and informal and casual English Language of the Americans. English is a lingua Franca which is acknowledged as a store house of knowledge and window onto world. At the start of the 21st century, most applied linguists were familiar with the fact that English is now spoken by a considerably greater number of non-native speakers than the native speakers. This incipient change in the status of English as an International language has opened a new vista of debate, namely, the intelligibility debate. It is assumed that English as an International Language has attained such a niche that its ownership by some group or some nation cannot be accepted as an authority, as it is connecting people across the globe through its mutual intelligibility trait. Those who can use it proficiently and even have command over its idiomatic use, whatever accent they may have must be acknowledged. The idea of following RP has been challenged by linguists like Jennifer Jenkins, Barbra Sieldhofer, Jonna Przedlacka, Katerzyna, etc and defended by Peter Trudgill and others of his school insist on the importance of a standard accent to be followed. This school says that every language has its own peculiar patterns which should be maintained while acquiring it otherwise that particular language will lose its peculiar flavor and identity and would gradually be lost like many other languages which could not resist simplification campaigns and eventually lost their originality. The current study explores this issue in Pakistani academic and professional situation among Pakistani Language practitioners with a survey based on the views of students and teachers through a questionnaire. The results show that all groups are in favor of an eclectic approach as is approved by Jenkins in her LFC proposal to NNS of English worldwide to facilitate convenience and ease. This study will initiate debates about an alternative way to teach and learn English as lingua franca.
\end{abstract}

Key words: Lingua franca, Intelligibility Debate, Pakistani English as a NN variety.

\section{INTRODUCTION}

English is a Lingua Franca. A lingua Franca is a language that comes from an entirely different cultural background and is taken over by the people whose first language is some other but they use it as a language of contact and utility. A definition of ELF in its purest form is by Firth, 'a contact language between persons who share neither a common native tongue nor a common (national) culture, and for whom English is the chosen foreign language of communication',cited in Siedlhofer.[14]. It has become a very popular term ELF, along with EIL(English as an International Language) . In today's globalized world English has become a symbol of immense political, social, and economic power, as Kachru[10],[11], reminds us, it is 'a communicative tool of immense power'. Pakir raises the important question, How this tool is used in the Outer Circle is a concern.[12]. 
English is heavily used as an international as well as an intra-national lingua franca. We focus on international English (IE), world Englishes (WE), and English as a lingua franca( ELF) as constructs, paradigms, or movements, and their implications. This paper, based on the theory and research in different paradigms begins with the notion that these three forms currently hold sway in the study of English throughout the world. The learners in Pakistan study English mainly for two reasons:

a) To acquire higher education in different fields.

b) To get good jobs.

English as a Lingua Franca possesses a vast geography, a compressed history, and enjoying progress at an accelerative speed. Crystal[6] realized the fact that English as a worldwide presence is not the same phenomenon everywhere as Crystal [6]. Jenkins[8],[9], has proposed a solution for the ever agonizing problem of those who are learning English as a second language and finding English pronunciation a herculean job to master. In her proposal, which is called Lingua Franca Core (LFC), Jenkins [8],[9], has redefined and classified pronunciation errors covering sociolinguistic and regional variations. This allows NNS to speak in their own regional accents without being regarded as error. Which presented a great solution to the frustration and futility of attempts to gain native or near-native like ability of learning all of the features of English pronunciation. Our Pakistani students are also lacking in oral proficiency due to confusion caused by difference in orthographic and pronunciation systems of English. A Simplified version of pronunciation offered by Jenifer Jenkins can be great help.

\section{THE PURPOSE OF THE STUDY}

The purpose of the study is to check the response of the seasoned Pakistani teachers and students towards current global trends in English language teaching and learning experiences especially concerning importance of local accents along with RP standard to relieve the students' burden of mastering difficult sounds and accents that are unfamiliar to the non native ear.

\section{SIGNIFICANCE OF THE STUDY}

Language teaching has been observed to be almost the same everywhere in Pakistan. There might be serious flaws in methodology, but language teachers are made to adopt them due to organizational difficulties, limited resources or time pressure to complete syllabus before exams, and an examination system which is focussed on written exams.These are the conditions which are beyond our control. The current study has tried to look for some other ways for the benefit of the students to combat with current challenges of communication in this globalized world of widening horizons by presenting intelligibility debate going on worldwide for the consideration of our worthy teachers and students.

\section{Hypothesis}

It is assumed that simplification in pronunciation will create ease in oral proficiency .

\section{Objectives}

To help the teachers and students in creating a new perception about acquiring proficiency in communicative skills

To help the teachers to understand the importance of teaching integrated skills

To draw the attention of the teachers towards some positives points of an alternative pronunciation system. 


\section{Research Questions}

\section{RESEARCH QUESTIONS}

1. How far a change in the pronunciation system(LFC Model) is effective in increasing proficiency among student's language skills?

2. What is the opinion of the PE users about LFC as an alternative pronunciation system?

\section{Delimitations of the Study}

1. This research is delimited to the teachers of English teaching at graduation level and the students studying in BA and BS.

2. The focus of this research will be on the students of Discipline of English in three Colleges at Sialkot.

3. Only pronunciation and difficulty in mastering oral skills is focused.

4. Response towards simplification of the pronunciation model as proposed by LFC model has been evaluated.

\section{What is Evaluation?}

Evaluation may be defined as a process of collecting information about the worth and standard of a particular project, individual, institution or book [2]. The process of evaluation can take place either during a project or after the completion of a project. Best [2] has, very aptly, remarked that evaluation is a process used to determine what has happened during a given activity or in an institution. The purpose of evaluation is to see if a given program is working, an institution is successful according to the goals set for it, or the original intent is being successfully carried out.

\section{The Current Study}

The researcher was convinced that there is a need to reform and reconstruct English Language Teaching in Pakistan to keep ourselves abreast of the modern trends in TEFL, TESOL and to make it more rewarding and relevant for the students to enhance their communicative skills. This can be done by simplifying the corpus of English pronunciation .On the basis of extensive data collected in multilingual EFL classes, Jennifer Jenkins modified the Common Core so as to take the reality of fully EIL into account. The resulting Lingua Franca Core identifies 7 areas in which it is essential to eliminate errors in our students' pronunciation: Vowel quantity, Consonant conflations, Phonetic realisations, Consonant cluster simplification, Prominence and weak forms, Tone groups, Nuclear/contrastive stress but not tone. The researcher wanted to know the difficulties of Pakistani students and the opinion of the Pakistani teachers and students about this debate regarding simplification on phonological level to create better intelligibility level and proficiency by accepting local accents .

\section{RESEARCH DESIGN}

As the purpose of this study is to evaluate the Intelligibility Debate from the perspectives of teachers and students. A self-reported questionnaire consisting of items in different sections has been used to illicit information from the students and teachers. Descriptive and inferential statistics were collecte through the questionnaire and document survey. On the basis of purpose, both quantitative and qualitative methods were used. The researcher herself is teaching at GCWU, Sialkot so her observations as participant observer were also there. The participants' responses are coded and tabulated on the basis of frequency of occurrence and mean value which are graphically presented with help of bar graphs. 


\section{CIPP Model}

\section{METHOD}

The CIPP model of evaluation was developed by Daniel Stufflebeam[8],[9],and colleagues in the1960s then improved and applied to educational studies. This evaluation model requires the evaluation of context, input, process and product in judging a program's value.

\section{Population and Sample}

The whole teaching faculty of English Language at graduate level and students studying at this level are the population but due to the constraints of time and resources researcher has delimited it to her own institution. The researcher will use random sampling method. Sample will be the teachers and students teaching and studying at Government Post Graduate College For Woman, Sialkot. Two Samples, Teachers sample and students sample will be used.

\section{General background of the students:}

The students who were given this questionnaire to fill were 19 to 21 year old. They have been studying English for the 8 to 9 years. These were divided into three groups:

1. Bachelor' of Arts (BA) Arts Group:

Their medium of instruction at learning at school was mixed both Urdu and English; those coming from English medium schools and those coming from Urdu medium schools were studying the same syllabi at college. Most of the students were studying subjects like Political Science, Education , Islamic studies , Psychology ,Urdu Literature, Home Economics at intermediate level ,comprised Arts Group and their need to use the English at this level was to pass the Exam by obtaining good marks in BA.

2. Bachelors' of Science (B.Sc.) Science Group:

They were studying Science subjects like Zoology, Botany, Chemistry, Physics, Mathematics and Statistics in B.Sc. comprising Science Group.

3. BS FYDP Group:

They were studying In BS FYDP in both arts and science subjects from semester 1 to semester 4 . The researcher had included the students of four batches because they had completed their two years of education in this new system and were equivalent to BA two years' students. The target population that the researcher aimed at to gather data for the questionnaire consisted of all the students taking BS classes in 2009-2010 academic years at Govt. Post Graduate College for Women, Sialkot.

4. General background of the teachers

Teachers' age was in between 35 to 50 years. They were all well experienced in teaching at both BA and BS level. They have been teaching English for last ten to twenty or so years. They had gone through both the systems right from teaching phase to evaluation phase so could easily compare and contrast pros and cons of the two syllabi and systems overall.

Table1 shows the details about Parental Educational Background (per 10 participants)

\begin{tabular}{|l|l|l|l|l|l|l|l|}
\hline Level & judges & lawyers & doctors & bankers & businessmen & teachers & students \\
\hline Masters & $80 \%$ & $50 \%$ & $70 \%$ & $40 \%$ & $10 \%$ & $60 \%$ & $10 \%$ \\
\hline bachelor & $20 \%$ & $40 \%$ & $20 \%$ & $40 \%$ & $10 \%$ & $40 \%$ & $10 \%$ \\
\hline HSS & $00 \%$ & $10 \%$ & $10 \%$ & $20 \%$ & $40 \%$ & $00 \%$ & $30 \%$ \\
\hline SS & $00 \%$ & $00 \%$ & $00 \%$ & $00 \%$ & $50 \%$ & $00 \%$ & $50 \%$ \\
\hline Below & $00 \%$ & $00 \%$ & $00 \%$ & $00 \%$ & $00 \%$ & $00 \%$ & $00 \%$ \\
\hline
\end{tabular}




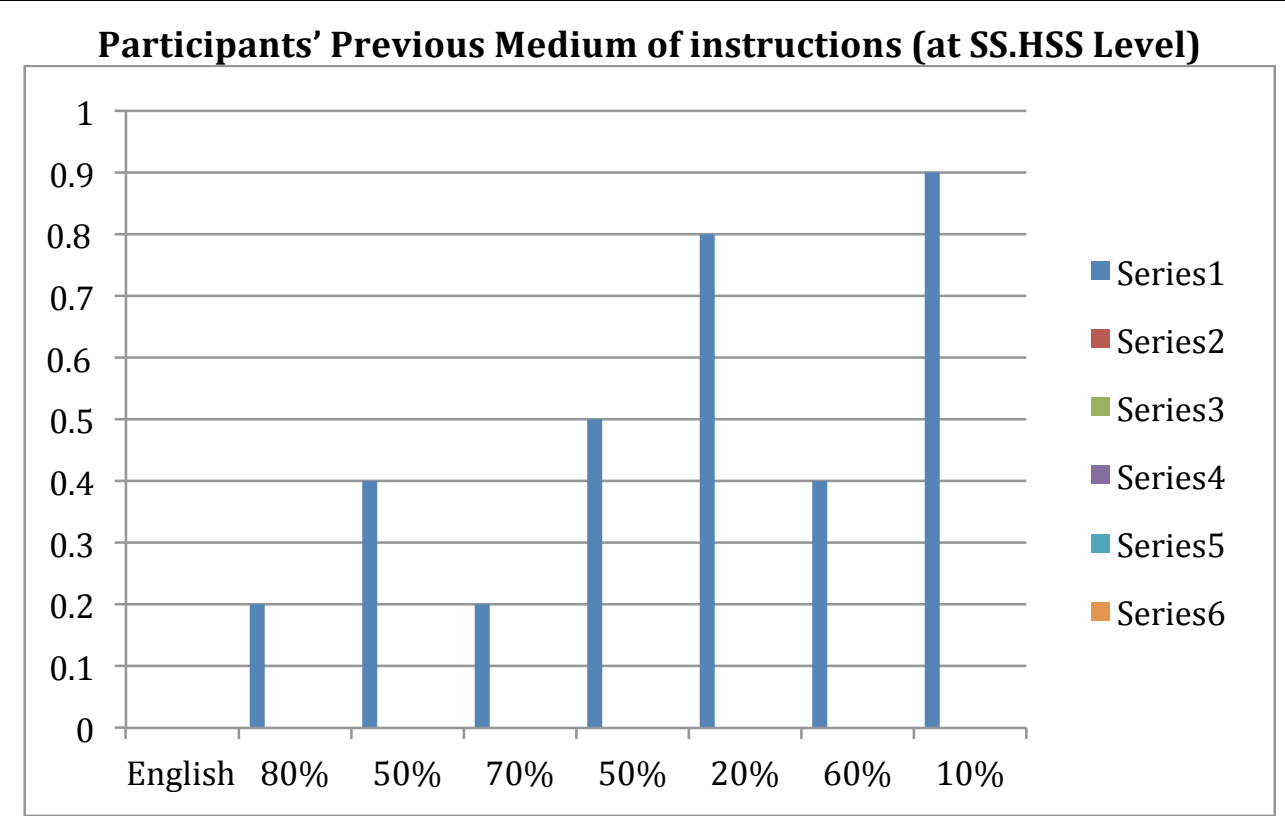

\section{Data Collection Method}

Both qualitative and quantitative data were collected in this evaluation study. Quantitative research is one of the research methodologies relying heavily on numbers in reporting results, sampling and provision of estimated instrument, reliability and validity [2]. Similarly, quantitative researchers seek to establish relationships between variables and look for and sometimes explain the causes of such relationships [13].As for qualitative source of data, along with written documents, the instructors were interviewed individually to comprehend their perceptions on the effectiveness of the program implemented. Qualitative data are collected mainly in the form of words or pictures and seldom involve numbers. Content analysis is a primary method of data analysis [2]. The quantitative data was presented and analyzed by tabulation of percentages, means and frequency of occurrences. The qualitative data was analyzed through content analysis. This data was presented in Graphic form.

\section{Data Collection Tools/Instrument}

1. The Questionnaire( Students)

2. The Questionnaire (Teachers)

3. Interview Method

\section{Detail of the Questionnaire}

\section{Part 1- Context- (Demographic Information)}

This part of the questionnaire aimed to obtain information on the students' age, gender, department enrolled, educational background of parents and type of high school graduated to know the medium of instructions previously taken.

\section{Part 2 - Context- (Overall perceptions of emphasis on skills)}

This part was designed in order to find out the participants' perceptions on the frequency of emphasis put on four skills. Part 3-Input - (Participants' perceived competencies in four skills)

The teaching of pronunciation in the classes and amount of time deputed to practice.

\section{Part-4- Process and Product- (Grading the problems of the participants)}

This part was designed to know the problems in acquiring proper fluency in speaking skills. 


\section{Data Collection Procedure}

Before conducting the questionnaire, the researcher explained the details of the study to the administration of the institution to get necessary permission for conducting the study.

Moreover, 20 teachers were interviewed to fill in the gapes left in the questionnaire. The schedules were set up in convenience of the interviewees. After giving the respondents background information about the study, the researcher assured the interviewee of confidentiality as no unauthorized persons would have access to their answers. The researcher was fully aware of the importance of enabling the informant to be at ease to obtain a high rate of participation. As a technique to record the answers, the interviewer chose to write down the responses immediately. Each interview approximately took 20 minutes and at the end of the interview, the researcher thanked the interviewees earnestly for their cordial cooperation.

\section{Treatment of Data Collected}

The collected data was processed properly to get reliable results data was processed. By sifting editing, coding, classifying and Tabulating the raw data before final analysis. This was done in order to avoid any inconvenience after wards in interpreting responses of the participants.

\section{Context}

\section{DATA ANALYSIS, FINDINGS AND DISCUSSION}

\section{Participants' Characteristics, Their Demographic Information .}

The participants of the study were regular students and other professionals of GPGC/W Sialkot. The other participants were also form Sialkot They belonged to almost all classes and have mixed background whose parents have educational level mostly between HSS to Masters.

\section{Participants' Parents' educational background}

The teachers, judges, lawyers, doctors, businessmen and bankers who participated in the study also belong to a mixed background with a mixed parental educational background the participants were asked to provide information about their parents' educational background in order to know the amount of help in studies at home and the frequency of use of English language at home as their communicative language.

Table 1 shows the details about this.

Parental Educational Background (per 10 participants)

\begin{tabular}{|l|l|l|l|l|l|l|l|}
\hline Level & judges & lawyers & doctors & bankers & businessmen & teachers & students \\
\hline Masters & $80 \%$ & $50 \%$ & $70 \%$ & $40 \%$ & $10 \%$ & $60 \%$ & $10 \%$ \\
\hline bachelor & $20 \%$ & $40 \%$ & $20 \%$ & $40 \%$ & $10 \%$ & $40 \%$ & $10 \%$ \\
\hline HSS & $00 \%$ & $10 \%$ & $10 \%$ & $20 \%$ & $40 \%$ & $00 \%$ & $30 \%$ \\
\hline SS & $00 \%$ & $00 \%$ & $00 \%$ & $00 \%$ & $50 \%$ & $00 \%$ & $50 \%$ \\
\hline Below & $00 \%$ & $00 \%$ & $00 \%$ & $00 \%$ & $00 \%$ & $00 \%$ & $00 \%$ \\
\hline
\end{tabular}




\section{Participants' Previous Medium of instructions (at SS.HSS Level)}

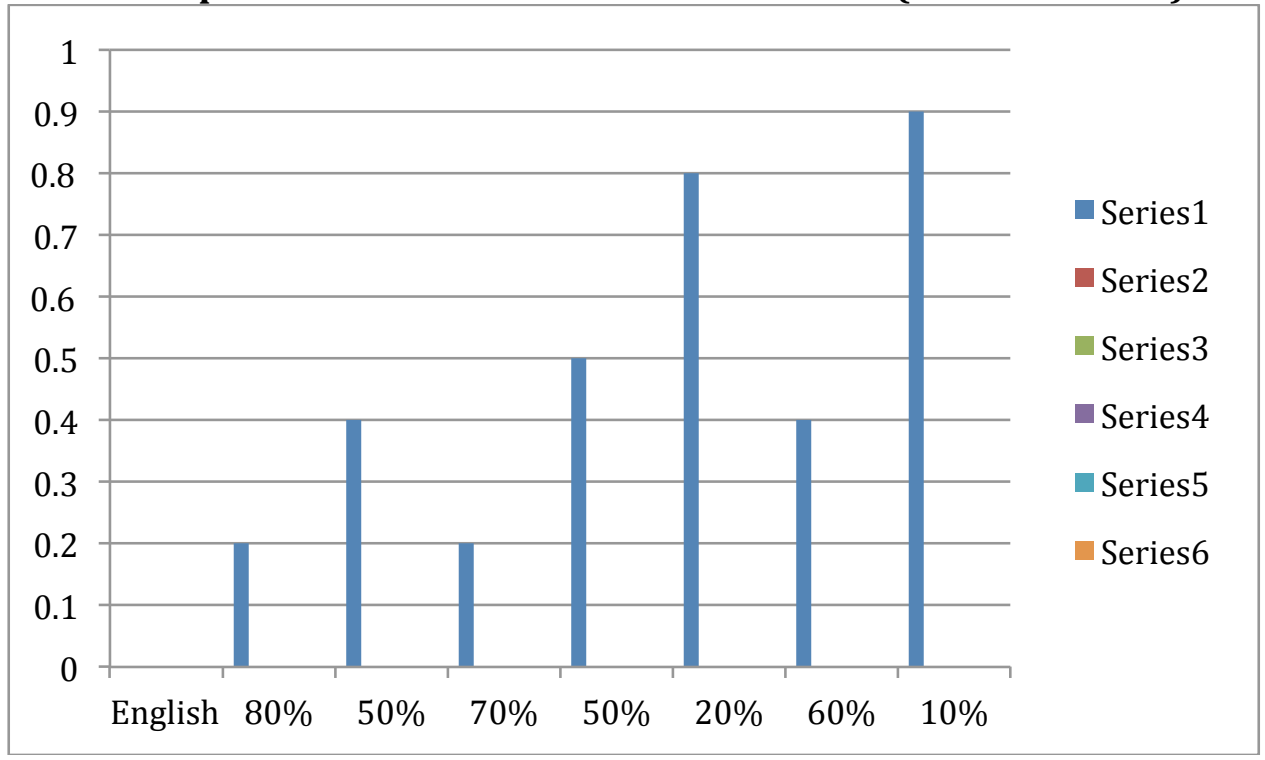

The above graph shows that the education level of the participants of the study is between Intermediate and Graduation. The Parents of very few has Master level qualification.

The Participants who are participating in the study are students and professionals.

Students are studying at the college are of bachelor's level, have passed their HSS exams (Intermediate) with Arts and Science both in Urdu and English medium. All the students are at secondary or tertiary level of English Language usage so it is expected that they can understand reading and writing in English along with listening to and speaking to their teacher in this foreign language. All the professionals have read it at higher level studies and are using it practically in all their official and professional communication.

\section{The professional group has basic proficiency level of English language. Table 2 presents} this detail.

Table 2 Medium of Instructions.(at SS.HSS Level)

\begin{tabular}{|l|l|l|l|l|l|l|l|}
\hline Level & judges & lawyers & doctors & bankers & businessmen & teachers & students \\
\hline English & $80 \%$ & $50 \%$ & $70 \%$ & $50 \%$ & $20 \%$ & $60 \%$ & $10 \%$ \\
\hline Urdu & $20 \%$ & $40 \%$ & $20 \%$ & $50 \%$ & $80 \%$ & $40 \%$ & $90 \%$ \\
\hline Punjabi & $00 \%$ & $00 \%$ & $00 \%$ & $00 \%$ & $00 \%$ & $00 \%$ & $00 \%$ \\
\hline Sindhi & $00 \%$ & $00 \%$ & $00 \%$ & $00 \%$ & $00 \%$ & $00 \%$ & $00 \%$ \\
\hline Pushto & $00 \%$ & $00 \%$ & $00 \%$ & $00 \%$ & $00 \%$ & $00 \%$ & $00 \%$ \\
\hline
\end{tabular}




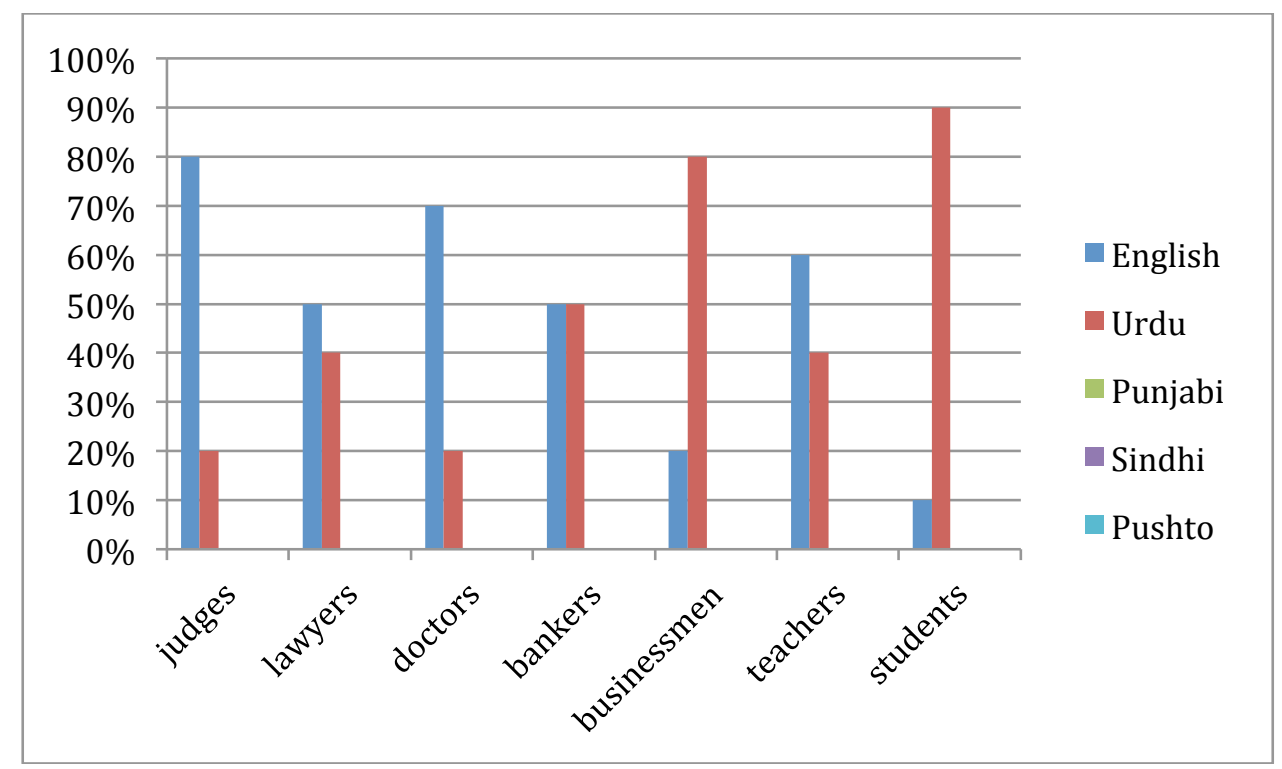

The above graph shows that mostly the medium of instruction of the participants is Urdu and Punjabi. This is why the phonological patterns of these two languages effect participants Pronunciation of L2 e.g. English.

\section{Participants' L1 (Mother Tongue)}

This part shows the information about the first language of the participants because it is expected that L1 interferes in acquiring L2.Features of Urdu, Punjabi, Pushto and Sindhi were studied. The phonology of all these languages was compared to detect the problematic sounds, patterns, and articulatory problems which hinder proficiency in English.

Table 3: Participant's L1 (Mother Tongue)

\begin{tabular}{|l|l|l|l|l|l|l|l|}
\hline level & judges & lawyers & doctors & bankers & businessmen & teachers & students \\
\hline English & $00 \%$ & $00 \%$ & $00 \%$ & $00 \%$ & $00 \%$ & $00 \%$ & $00 \%$ \\
\hline Urdu & $20 \%$ & $20 \%$ & $20 \%$ & $50 \%$ & $20 \%$ & $20 \%$ & $20 \%$ \\
\hline Punjabi & $80 \%$ & $80 \%$ & $80 \%$ & $80 \%$ & $80 \%$ & $80 \%$ & $80 \%$ \\
\hline Sindhi & $00 \%$ & $00 \%$ & $00 \%$ & $00 \%$ & $00 \%$ & $00 \%$ & $00 \%$ \\
\hline Pushto & $00 \%$ & $00 \%$ & $00 \%$ & $00 \%$ & $00 \%$ & $00 \%$ & $00 \%$ \\
\hline
\end{tabular}




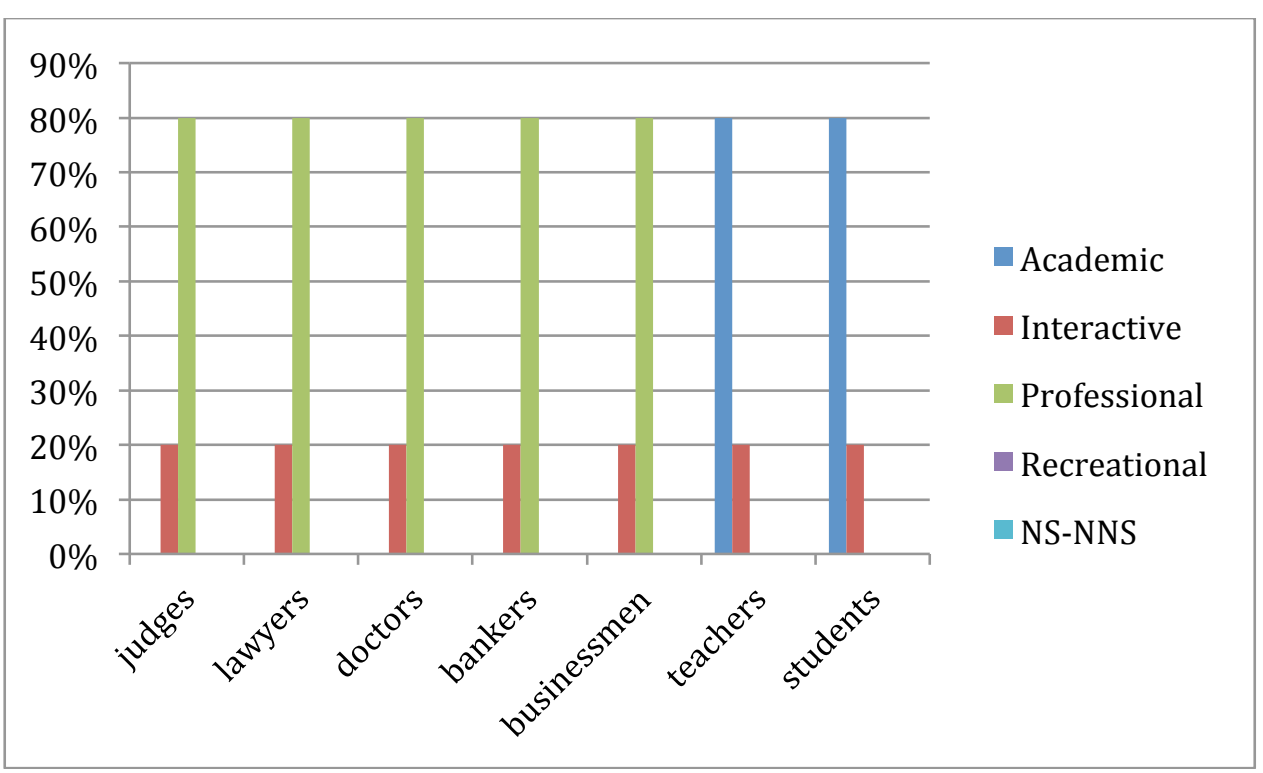

The above graph shows that mostly the Mother Tongue-L1 of the participants is Urdu and Punjbi. This is why The phonological patterns of these two languages affect participants Pronunciation of L2 e.g. English.2) Input

\section{Current Situation of the Participants, their needs and Provisions}

This section aims at the investigations of the human and material side of the study. The students and the other practitioners who were targeted population were studied on the one hand and the opportunities provided to them for getting proficiency in oral-aural skills were studied in detail on the other.

At this stage of the evaluative study, the researcher's own observations as a participant observer were of a great help, as she has been the student as well as part of the teaching faculty for the last 18 years at the site of research (GPGC/W,Sialkot).

Need Analysis was performed by asking all the participants to mark the purpose of their learning English language. Table 4 reports the types of purpose of each group.

Table 4 Need Analysis For English Language Communication

\begin{tabular}{|l|l|l|l|l|l|l|l|}
\hline Purpose & judges & lawyers & doctors & bankers & businessmen & teachers & students \\
\hline Academic & $00 \%$ & $00 \%$ & $00 \%$ & $00 \%$ & $00 \%$ & $80 \%$ & $80 \%$ \\
\hline Interactive & $20 \%$ & $20 \%$ & $20 \%$ & $20 \%$ & $20 \%$ & $20 \%$ & $20 \%$ \\
\hline Professional & $80 \%$ & $80 \%$ & $80 \%$ & $80 \%$ & $80 \%$ & $00 \%$ & $00 \%$ \\
\hline Recreational & $00 \%$ & $00 \%$ & $00 \%$ & $00 \%$ & $00 \%$ & $00 \%$ & $00 \%$ \\
\hline NS-NNS & $00 \%$ & $00 \%$ & $00 \%$ & $00 \%$ & $00 \%$ & $00 \%$ & $00 \%$ \\
\hline
\end{tabular}




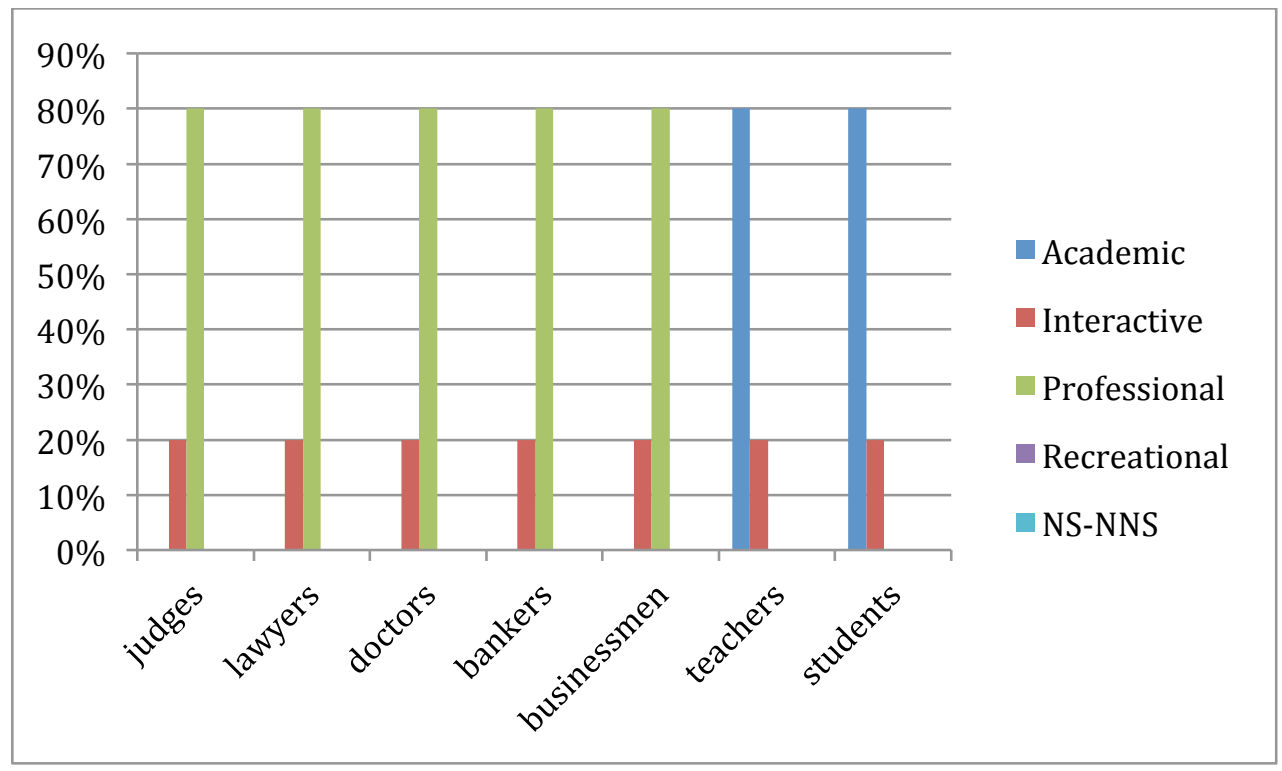

The above graph shows that mostly the participants need English for academic, interactive and professional purposes for. This is why they want fluency and ease in communication skills. They want to be intelligible to all other NNS and NS of English.

\section{Current Situation of the Participants, their Problems}

Problems in getting mastery over Oral- Aural Skills in students and professionals were studied. The data was collected from the students, teachers and other professional language practitioners through a self reported questionnaire to know the background, needs, existing level of competencies, their problems and suggested remedial measures.

Part1: Shows personal information of the respondents, (Table 1)

Part2: Shows participant' overall Perception of Emphasis on Skills ,(Table 8)

Part3: Shows participants' problems in speaking and listening English.,(Table 5)

.(Table 4.9)

Part4: Explores problematic areas in Pronunciation (Table 5)

,Part5: Suggests remedies, (Table 7)

Part6: Settling the responsibility Table (9)

Part 7: Seeks information about Simplification Compagain -LFC model.(Table-10)

The typical language learning experience in Pakistan has no or little space for the improvement of the four communication skills, especially listening and speaking skills. Our educational system is not geared to teach and test the oral skills of the learners. For our students syllabus content is one of the main causes for the neglect of speaking skills. They are not provided with the situations which can trigger their creativity. English is not treated as a language; it is taken as a subject. In the textbooks there are prose lessons for which translation method is used and rote learning is done from guide books

The above graph below shows that mostly the participants have problems of Fluency, Rhythm of RP, Accent,L1 interference and lack of confidence while using English for academic, interactive and professional purposes. This is why they want fluency and ease in communication skills. They want to be intelligible to all other NNS and NS of English. 
Table 5: Problems while Speaking English

\begin{tabular}{|l|l|l|l|l|l|l|l|}
\hline type & judges & lawyers & doctors & bankers & businessmen & teachers & students \\
\hline Pronunciation & $00 \%$ & $00 \%$ & $00 \%$ & $00 \%$ & $00 \%$ & $20 \%$ & $70 \%$ \\
\hline vocabulary & $20 \%$ & $20 \%$ & $20 \%$ & $20 \%$ & $20 \%$ & $20 \%$ & $10 \%$ \\
\hline Accent & $80 \%$ & $80 \%$ & $80 \%$ & $80 \%$ & $80 \%$ & $40 \%$ & $90 \%$ \\
\hline Rhythm ofRP & $90 \%$ & $90 \%$ & $90 \%$ & $90 \%$ & $90 \%$ & $40 \%$ & $90 \%$ \\
\hline Fluency & $100 \%$ & $100 \%$ & $100 \%$ & $100 \%$ & $100 \%$ & $100 \%$ & $100 \%$ \\
\hline hesitation & $00 \%$ & $00 \%$ & $00 \%$ & $00 \%$ & $00 \%$ & $40 \%$ & $100 \%$ \\
\hline L1 effect(PE) & $70 \%$ & $70 \%$ & $50 \%$ & $60 \%$ & $90 \%$ & $40 \%$ & $80 \%$ \\
\hline Grammar & $00 \%$ & $80 \%$ & $70 \%$ & $60 \%$ & $90 \%$ & $10 \%$ & $50 \%$ \\
\hline Confience & $00 \%$ & $00 \%$ & $00 \%$ & $00 \%$ & $10 \%$ & $70 \%$ & $90 \%$ \\
\hline
\end{tabular}

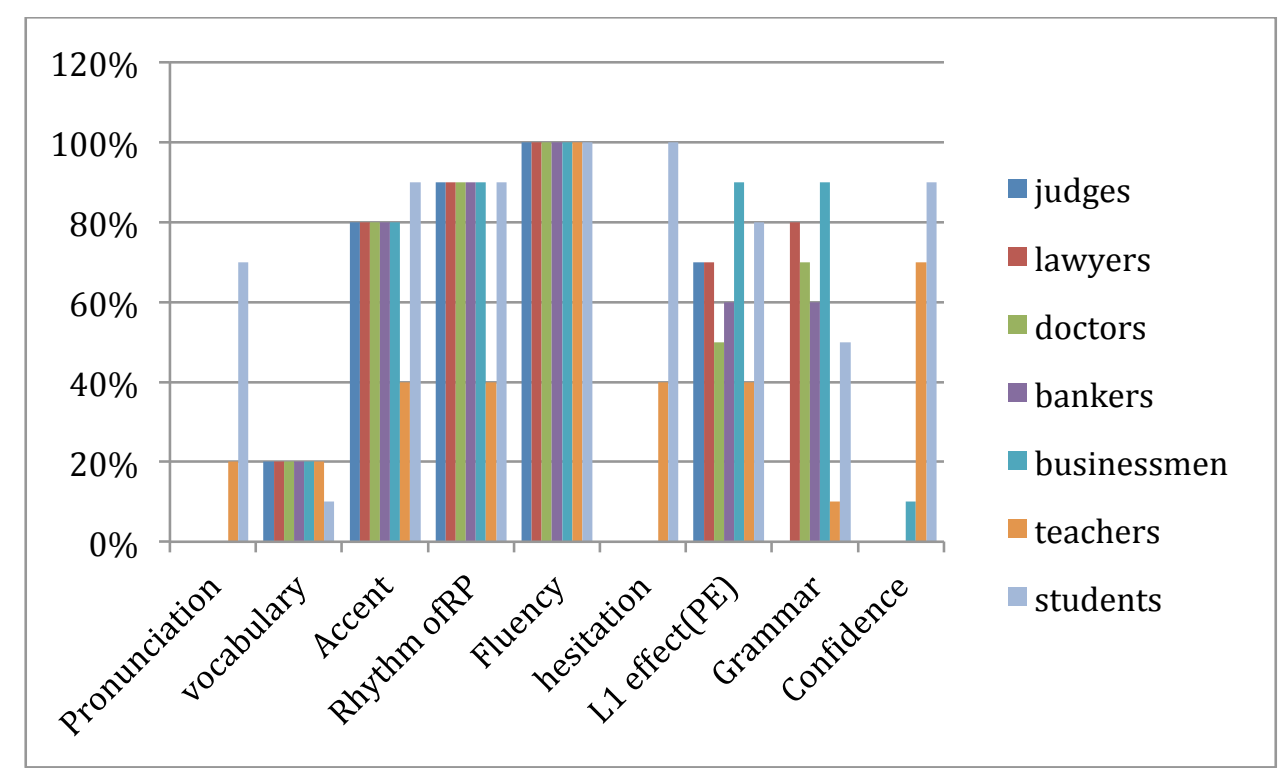

Table 6Problems while Listening English

\begin{tabular}{|l|l|l|l|l|l|l|l|}
\hline type & judges & lawyers & doctors & bankers & businessmen & teachers & students \\
\hline Pronunciation & $00 \%$ & $00 \%$ & $00 \%$ & $00 \%$ & $00 \%$ & $20 \%$ & $70 \%$ \\
\hline vocabulary & $20 \%$ & $20 \%$ & $20 \%$ & $20 \%$ & $20 \%$ & $20 \%$ & $10 \%$ \\
\hline Accent & $80 \%$ & $80 \%$ & $80 \%$ & $80 \%$ & $80 \%$ & $40 \%$ & $90 \%$ \\
\hline Rhythm of RP & $90 \%$ & $90 \%$ & $90 \%$ & $90 \%$ & $90 \%$ & $40 \%$ & $90 \%$ \\
\hline Fluency/Speed & $100 \%$ & $100 \%$ & $100 \%$ & $100 \%$ & $100 \%$ & $100 \%$ & $100 \%$ \\
\hline hesitation & $00 \%$ & $00 \%$ & $00 \%$ & $00 \%$ & $00 \%$ & $40 \%$ & $100 \%$ \\
\hline L1 effect(PE) & $70 \%$ & $70 \%$ & $50 \%$ & $60 \%$ & $90 \%$ & $40 \%$ & $80 \%$ \\
\hline Grammar & $00 \%$ & $80 \%$ & $70 \%$ & $60 \%$ & $90 \%$ & $10 \%$ & $50 \%$ \\
\hline Confidence & $00 \%$ & $00 \%$ & $00 \%$ & $00 \%$ & $10 \%$ & $70 \%$ & $90 \%$ \\
\hline
\end{tabular}




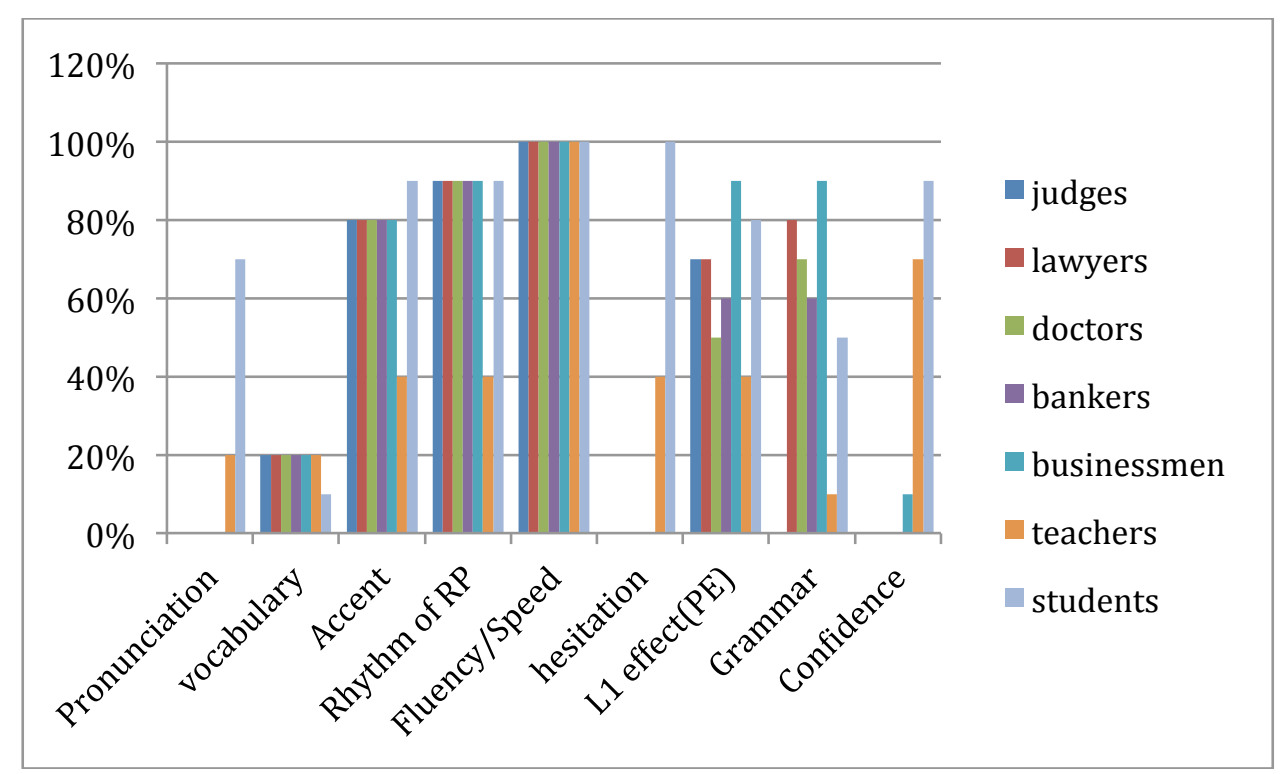

The above graph shows that mostly the participants have problems of Fluency, Rhythm of RP, Accent, L1 interference and lack of confidence while listening to English for academic, interactive and professional purposes. This is why they want fluency and ease in communication skills in both oral and aural .They want to be intelligible to all other NNS and NS of English.

\section{PRODUCT- CRUX OF THE PROBLEM}

Reviewing the questionnaires of all the participants the researcher got following information the researcher reached at Crux of the problem-Pronunciation.

Table 7

\begin{tabular}{|l|l|l|l|l|l|l|l|}
\hline \multicolumn{1}{|c|}{ type } & judges & $\begin{array}{l}\text { L the } \\
\text { awyers }\end{array}$ & doctors & bankers & businessmen & teachers & students \\
\hline Vowel s & $40 \%$ & $50 \%$ & $30 \%$ & $80 \%$ & $60 \%$ & $20 \%$ & $70 \%$ \\
\hline Diphthongs & $40 \%$ & $50 \%$ & $30 \%$ & $80 \%$ & $60 \%$ & $20 \%$ & $70 \%$ \\
\hline ConsonantClusters & $20 \%$ & $20 \%$ & $20 \%$ & $20 \%$ & $20 \%$ & $20 \%$ & $70 \%$ \\
\hline SE Accent & $80 \%$ & $80 \%$ & $80 \%$ & $80 \%$ & $80 \%$ & $40 \%$ & $90 \%$ \\
\hline Rhythm of RP & $90 \%$ & $90 \%$ & $90 \%$ & $90 \%$ & $90 \%$ & $100 \%$ & $100 \%$ \\
\hline Use of Stress & $100 \%$ & $100 \%$ & $100 \%$ & $100 \%$ & $100 \%$ & $100 \%$ & $100 \%$ \\
\hline Syllibification & $100 \%$ & $100 \%$ & $100 \%$ & $100 \%$ & $100 \%$ & $100 \%$ & $100 \%$ \\
\hline L1 effect(PE) & $70 \%$ & $70 \%$ & $50 \%$ & $60 \%$ & $90 \%$ & $40 \%$ & $80 \%$ \\
\hline weak forms & $00 \%$ & $80 \%$ & $70 \%$ & $60 \%$ & $90 \%$ & $90 \%$ & $90 \%$ \\
\hline Use of Schaw & $00 \%$ & $00 \%$ & $00 \%$ & $00 \%$ & $10 \%$ & $70 \%$ & $90 \%$ \\
\hline
\end{tabular}




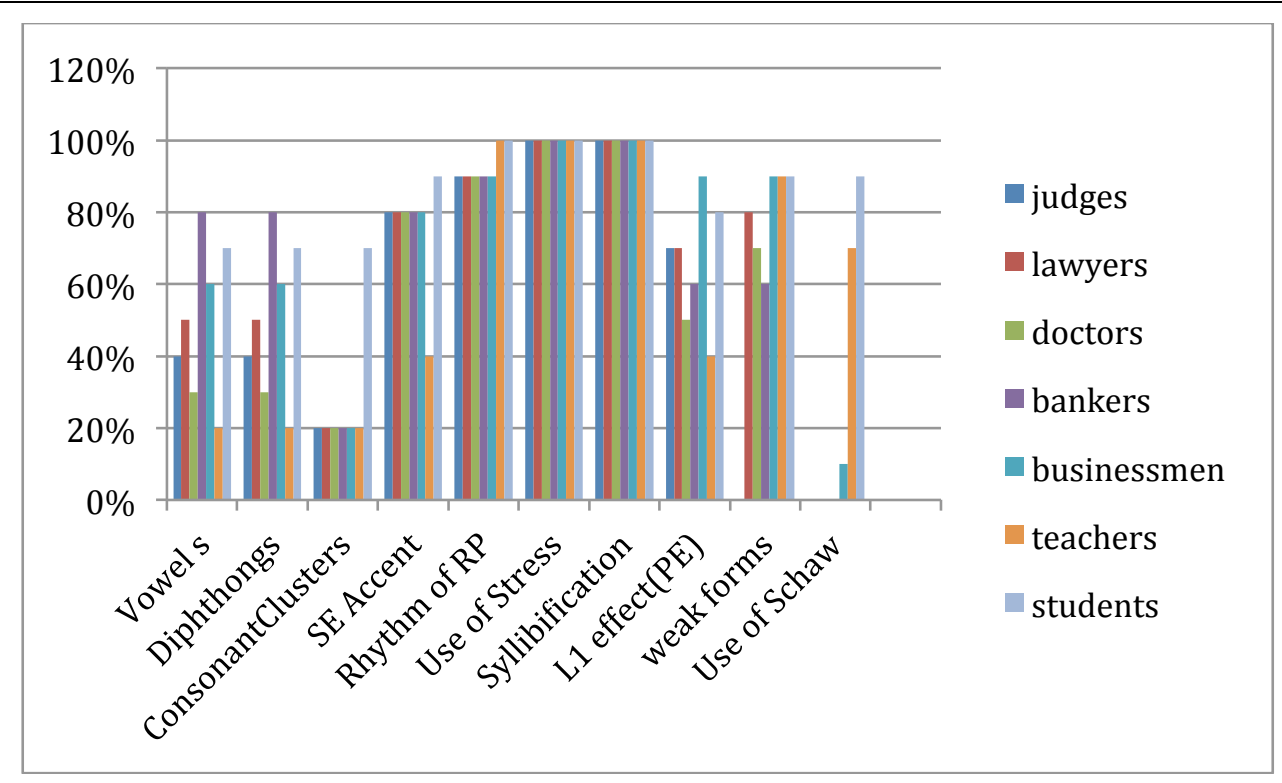

that mostly the participants have problems of Syllabification, Rhythm, Use of stress, SE accent, Use of Weak forms ,Use of schwa, L1 interference and use of simple vowels and glides especially while listening to English for academic, interactive and professional purposes . This is why they want fluency and ease in communication skills in both oral and aural .They want to be intelligible to all other NNS and NS of English.

Table 8: Grading of the Problems of PE Practitioners

\begin{tabular}{|l|l|l|l|l|l|l|l|}
\hline type & judges & lawyers & doctors & bankers & businessmen & teachers & students \\
\hline Use of stress & $100 \%$ & $100 \%$ & $100 \%$ & $100 \%$ & $100 \%$ & $100 \%$ & $100 \%$ \\
\hline syllybification & $100 \%$ & $100 \%$ & $100 \%$ & $100 \%$ & $100 \%$ & $100 \%$ & $100 \%$ \\
\hline Rhythm of RP & $90 \%$ & $90 \%$ & $90 \%$ & $90 \%$ & $90 \%$ & $100 \%$ & $100 \%$ \\
\hline SE Accent & $80 \%$ & $80 \%$ & $80 \%$ & $80 \%$ & $80 \%$ & $40 \%$ & $90 \%$ \\
\hline Vowels/glides & $70 \%$ & $70 \%$ & $50 \%$ & $60 \%$ & $90 \%$ & $40 \%$ & $80 \%$ \\
\hline Consonantcluster & $40 \%$ & $50 \%$ & $30 \%$ & $80 \%$ & $60 \%$ & $20 \%$ & $70 \%$ \\
\hline weakforms & $20 \%$ & $20 \%$ & $20 \%$ & $20 \%$ & $20 \%$ & $20 \%$ & $70 \%$ \\
\hline schaw & $00 \%$ & $80 \%$ & $70 \%$ & $60 \%$ & $90 \%$ & $90 \%$ & $90 \%$ \\
\hline spelling & $00 \%$ & $00 \%$ & $00 \%$ & $00 \%$ & $10 \%$ & $70 \%$ & $90 \%$ \\
\hline
\end{tabular}




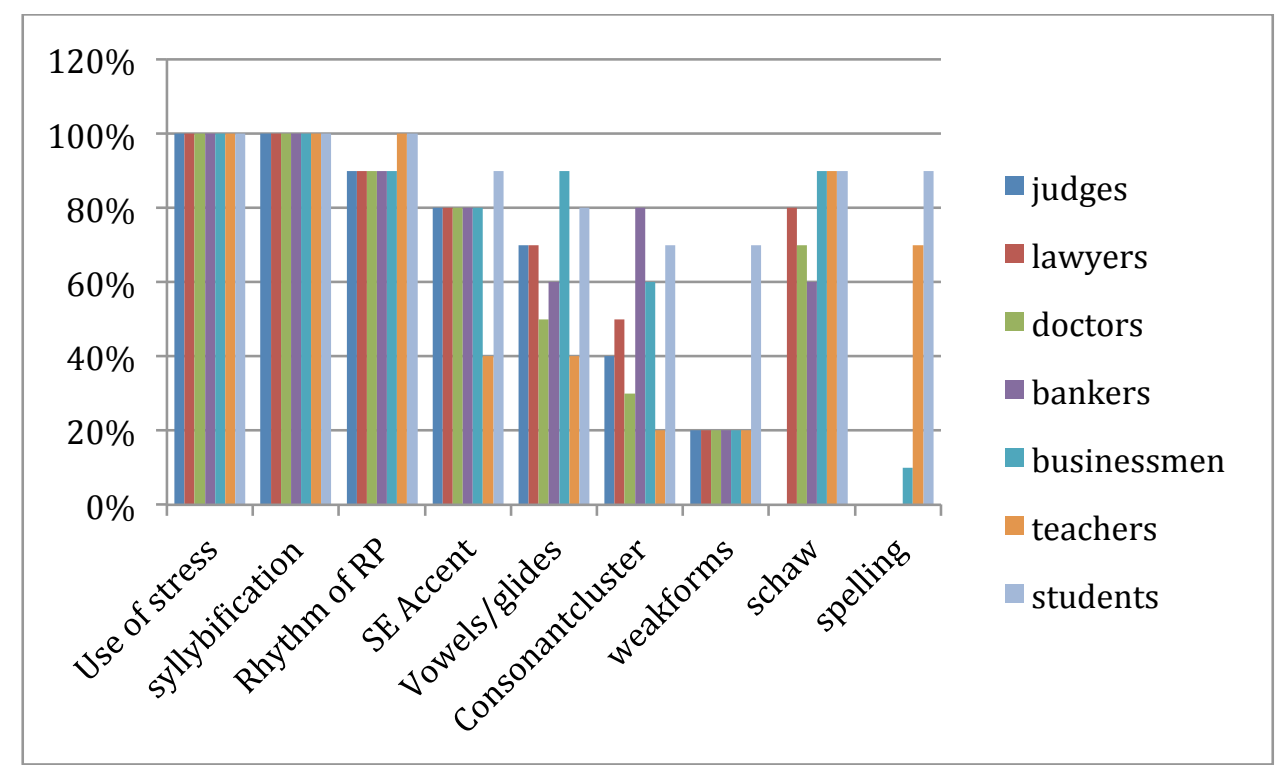

The above graph shows that mostly the participants have problems of Syllabification, Rhythm, Use of stress, SE accent, Use of Weak forms ,Use of schwa, L1 interference and use of simple vowels and glides especially while listening to English for academic, interactive and professional purposes. This is why they want fluency and ease .

\section{Determining the Responsibility of the Problem}

Who is responsible? (Table 9)

The respondents put responsibility on teachers.

The teachers accepted that not enough time is being allocated towards teaching of integrated skills and they welcomed this intelligibility debate. A new thought put forward by intelligibility debate. They showed mixed response as they were exam oriented which do not allow new experiments.

Table 9: Who is responsible?

\begin{tabular}{|l|l|l|l|l|l|l|l|}
\hline Type & judges & lawyers & doctors & bankers & businessmen & teachers & Students \\
\hline $\begin{array}{l}\text { Faulty ELT } \\
\text { methods }\end{array}$ & $100 \%$ & $100 \%$ & $100 \%$ & $100 \%$ & $100 \%$ & $100 \%$ & $100 \%$ \\
\hline Lack of Practice & $100 \%$ & $100 \%$ & $100 \%$ & $100 \%$ & $100 \%$ & $100 \%$ & $100 \%$ \\
\hline $\begin{array}{l}\text { BSE accent vs } \\
\text { PE accent }\end{array}$ & $100 \%$ & $100 \%$ & $100 \%$ & $100 \%$ & $100 \%$ & $100 \%$ & $100 \%$ \\
\hline $\begin{array}{l}\text { Inherent } \\
\text { TESOL } \\
\text { problems }\end{array}$ & $100 \%$ & $100 \%$ & $100 \%$ & $100 \%$ & $100 \%$ & $100 \%$ & $100 \%$ \\
\hline $\begin{array}{l}\text { Lack } \\
\text { Pronunciation } \\
\text { Model }\end{array}$ & $100 \%$ & $100 \%$ & $100 \%$ & $100 \%$ & $100 \%$ & $100 \%$ & $100 \%$ \\
\hline $\begin{array}{l}\text { Inherent } \\
\text { Phonotactics } \\
\text { of EL }\end{array}$ & $100 \%$ & $100 \%$ & $100 \%$ & $100 \%$ & $100 \%$ & $100 \%$ & $100 \%$ \\
\hline
\end{tabular}


The above table shows that mostly the participants have blamed Faulty ELT methods, Lack of Practice, BSE accent vs PE accent, Inherent TESOL problems, Lack of Pronunciation Model, Inherent Phonotactics of EL causing problem in academic, interactive and professional use of English. . This is why they want some change.

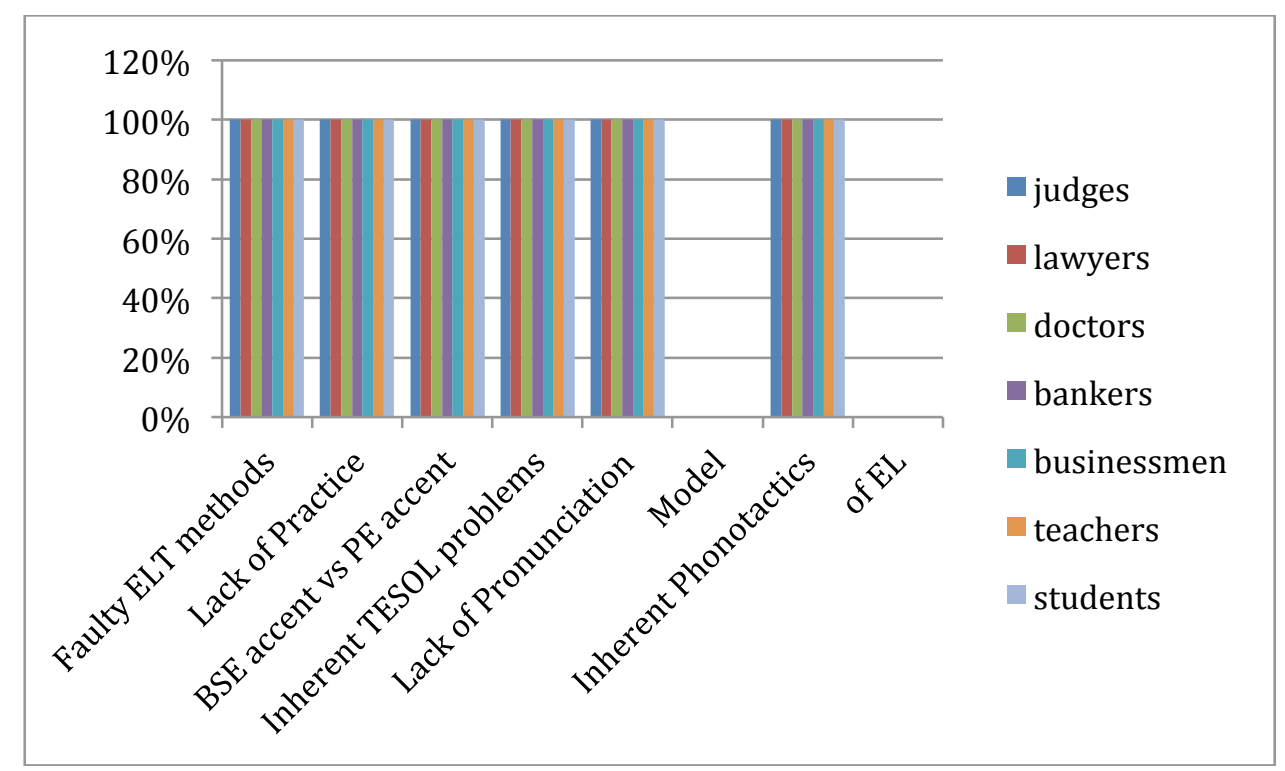

Some Possible Solutions were discussed.

Table 10 Some Possible Solutions

\begin{tabular}{|l|l|l|l|l|l|l|l|}
\hline Type & judges & lawyers & doctors & bankers & businessmen & teachers & Students \\
\hline PEaccent & $100 \%$ & $100 \%$ & $100 \%$ & $100 \%$ & $100 \%$ & $100 \%$ & $100 \%$ \\
\hline LFC-model & $100 \%$ & $100 \%$ & $100 \%$ & $100 \%$ & $100 \%$ & $100 \%$ & $100 \%$ \\
\hline $\begin{array}{l}\text { ELTRTraining } \\
\text { Courses }\end{array}$ & $100 \%$ & $100 \%$ & $100 \%$ & $100 \%$ & $100 \%$ & $100 \%$ & $100 \%$ \\
\hline AIOU Reformed & $100 \%$ & $100 \%$ & $100 \%$ & $100 \%$ & $100 \%$ & $100 \%$ & $100 \%$ \\
\hline Simplification & $100 \%$ & $100 \%$ & $100 \%$ & $100 \%$ & $100 \%$ & $100 \%$ & $100 \%$ \\
\hline
\end{tabular}

The above table shows that mostly the participants have favored PEaccent, LFC-model, ELTR Training Courses, AIOU Reformed courses, Simplification in academic, interactive and professional use of English. This is why they want some change.

\section{CONCLUSION}

This study was performed in order to present Intelligibility Debate and to evaluate the effectiveness of this LFC model as compared to RP for the consideration of PE language Practitioner. It was very warmly welcomed by all the groups of the participants. Everyone was facing problems of pronunciation of one sort or other and wanted some solution.Findings of the study show that the teachers want significant variations across corpora but are reluctant to accept the diachronic change. Mostly the participants considered the teaching of native-like accent to be very important. They attached a social prestige with acquiring native like accent (acrolect) as a reminder of colonial thought. The educated variety of Pakistani English, has evolved over a period of prolonged use in the academic, administrative, legal, commercial and diplomatic spheres of national life in Pakistan.(Haque,R,A:2003). Some unwritten, indistinct norms regarding pronunciation existed, but were never explicitly stated (Saleemi,A,P: 1985). 
This fact usually became obvious at the time of interviews and selection tests when a basic expectation was conformity not to the RP standards, but to the locally accepted norms; those not conforming to 'the norms' were marginalized. Baumgardner (1989) maintains that Pakistani English has developed its own linguistic identity and culture that does not make it inferior to British Standard English. Rahman (1990) who investigated the sociolinguistic variation in Pakistani English with a focus on phonology, syntax, morphology and lexis, called for the need for a published and easily available description of Pakistani English as an institutionalized non-native variety. Pakistani English has now established its own linguistic identity and justification with its distinct phonological features, syntactic differences and culture-specific lexicon.

As far as some model accents is concerned most of the teachers favored British English as the main model accent taught in textbooks, followed by American and Australian English and considered Jennifer Jenkin s' LFC proposal is unusual in an academic publication. In the final conclusion we can say that it is not easy to have full command over all the macro skills, because it needs a number of requirements. If we talk to a native speaker of English, we should have much broader competency in pronunciation. We should be able to perceive all such sounds and words which are there in the native's active vocabulary, intuitively. So LFC simplified features in the following areas should be used in the interactive communication So a revised and simplified plan is needed. The language practitioners expressed discontentment about following RP or GA and want SPEA (Standard Pakistani English Accent) to some extent which can be improved by following Jenkins' proposal of LFC.

In-service training opportunities can help teachers to update their knowledge This can be done through AIOU's distant learning programmes, especially computer assisted language learning programmes (CALL, TEFL, TESOL, M.Ed., M. Phil, etc.)

Computer links and sites could be designed so as to help teachers find sufficient amount of materials, especially conversations with native speakers on line can be helpful.

\section{RECOMMENDATIONS}

In order to improve speaking skills in Pakistan, it is necessary that students ought to be trained in such a way that they could utilize these communication skills in their real life situation. This can be done only when they overcome their hesitation in the use of English language in the class. All the interaction between S-S And S-Teacher should be in English. In this way they will be corrected on the spot and encouraged to use it proficiently afterwards.

The teachers should be able to recognize the difference between the structural and functional use of English and teaching it as a subject. The instructional discourse in the class should be in very simple and easy English based on Jenifer Jenkins' highlighted points to provide the students an easy model of pronunciation to follow .

The teachers should be able to know and discriminate between sounds of English and their students' mother tongue, and solve the problem of unintelligibility if there comes any overlapping of sounds or omission of sounds. it is said that good listeners are good speaker; and good readers are good writers so the more teachers will use the simple English language in the class the more their students become comfortable in pronunciation. This will improve intelligibility level among them. 
Language teachers should be especially trained in all the four macro skills ,Listening, Speaking, Reading \& Writing. When this topic was discussed with the teachers trainers and their syllabi selectors they agreed that it should be included in the training plan of the English Language teachers. The worthy Chairman of AIOU , the largest available body who trains teachers with its programmers of ELT. TEFL,B Ed etc, was optimistic in introducing LFC as a new leaf turned in ELT training programmes.

Modern teaching methods should be applied in the classroom. The use of recordings of the common everyday talk played in the class can be of a great help in getting familiar with English Language rhythm. In this regard Communicative language teaching has proved to be an effective method.

In language teaching special emphasis must be given to speaking skills, because the more the learners speak, the more they pronounce correctly. Jenifer Jenkins wanted to use her model in the pedagogical area for the improvement of interactive skills of those students who have to go abroad for their higher studies. There they do not have to stick to any one accent but need to be intelligible to all of their class fellows who would have belonged to all around the world.

Our syllabus should be revised thoroughly. It should be divided into structural and functional part, where there is also some space for situational syllabus. In this kind of syllabus, the teachers will be forced to teach the skills and students will be compelled to learn all this. The students will also be aware of the fact that they are going to be tested in this regard. Our examination system should be developed in such a way as to test all the four skills, not only Reading and Writing.

\section{References}

1. Baumgardener, R. J. Ed.(1993) The English Language in Pakistan. Karachi. Oxford University Press.

2. Best, J.W., and Kahn, J.V. (2003). Research in education (9th ed.). Boston, MA: Pearson Education Company.

3. Brazil,D.( 1994).Pronunciation for Advanced Learners of English, Cambridge Univ. Press,

4. Crystal,D.(1995). The Cambridge Encyclopedia of the English Language. Cambridge Univ. Press.

5. Crystal D. (2003) English as a global language 2nd edition. Cambridge . Cambridge.

6. Haque, A,R, (1993).The Position and Status of English in Pakistan.In Baumgardener,R,J (Ed.) The English Language in Pakistan.Karachi.Oxford University Press.

7. Jenkins, J. (2000).The Phonology of English as an International Language.Oxford: Oxford University Press.

8. Jenkins,J.(2004). 'Misinterpretation, Bias, and Resistance to Change', In Dziubalska-Kołaczyk, Katarzyna; Przedlacka, Joanna (Eds.).(2008). English Pronunciation Models: A Changing Scene. (2nd ed.). Beatrice Szczepek Reed, Centre for English Language Education, University of Nottingham, UK: Peter Lang AG

9. Kachru,B.B.(1982) The Indianization of English: The English Language in India, Oxford University Press, New Delhi

10. Kachru, Y (1999) Culture, Context and Writing, in eds. Michael H Long and Jack C Richards, The Cambridge Applied Series 1999, Cambridge University Press.

11. Pakir, A(2003). English as Lingua Franca and Its Implications for Lexicography. Paper presented at ASIALEX 2003, 27-29 August 2003, Meikei University, Tokyo, Japan. (Keynote Paper).

12. Rahman, T. (1990). Pakistani English: The linguistic description of a non-native variety of English.

13. Seidlhofer,B.(2004). 'Language Variation and Change: The Case of English as a Lingua Franca' . In Dziubalska-Kołaczyk, Katarzyna; Przedlacka, Joanna (Eds.).(2008). English Pronunciation Models: A Changing Scene. (2nd ed.). Beatrice Szczepek Reed, Centre for English Language Education, University of Nottingham, UK: Peter Lang AG[ 
14. Stufflebeam, D.L. (2000). The CIPP model for evaluation. In T.Kellaghan and D.L Stufflebeam (Eds). International handbook of educational evaluation, Part 1 (pp.31-62). Dordrecht: Kluwer Academic Publishers.

15. Trudgill, P. (2002).Sociolinguistic Variation and Change. Edinburgh:Edinburgh University Press.

16. Trudgill,P.(2004). 'Native-speaker Segmental Phonological Models and the

17. English Lingua Franca Core'. In Dziubalska-Kołaczyk, Katarzyna; Przedlacka, Joanna (Eds.).(2008). English Pronunciation Models: A Changing Scene. (2nd ed.). Beatrice Szczepek Reed, Centre for English Language Education, University of Nottingham, UK: Peter Lang AG

18. Wells, V, J.( 1999). Which pronunciation do you prefer? IAFTEFL Issues149, IATEFL,.

19. Włodzimierz Sobkowiak.(2004). 'Why Not LFC?' . In Dziubalska-Kołaczyk, Katarzyna; Przedlacka, Joanna (Eds.).(2008). English Pronunciation Models: A Changing Scene. (2nd ed.). Beatrice Szczepek Reed, Centre for English Language Education, University of Nottingham, UK: Peter Lang AG 